\title{
Regulation by glycogen synthase kinase-3 of inflammation and $T$ cells in CNS diseases
}

\author{
Eléonore Beurel * \\ Department of Psychiatry and Behavioral Neurobiology, University of Alabama at Birmingham, Birmingham, AL, USA
}

Edited by:

Oksana Kaidanovich-Beilin, Samuel

Lunenfeld Research Institute, Canada

\section{Reviewed by:}

Jari Koistinaho, University of Eastern

Finland, Finland

Ye He, University of California

San Francisco, USA

\section{*Correspondence:}

Eléonore Beurel, Department of Psychiatry and Behavioral

Neurobiology, University of Alabama at Birmingham, 1720 Seventh Avenue South, SC1057, Birmingham, AL 35294-0017, USA.

e-mail: eleonore_beurel@hotmail.fr
Elevated markers of neuroinflammation have been found to be associated with many psychiatric and neurodegenerative diseases, such as mood disorders, Alzheimer's disease, and multiple sclerosis (MS). Since neuroinflammation is thought to contribute to the pathophysiology of these diseases and to impair responses to therapeutic interventions and recovery, it is important to identify mechanisms that regulate neuroinflammation and potential targets for controlling neuroinflammation. Recent findings have demonstrated that glycogen synthase kinase-3 (GSK3) is an important regulator of both the innate and adaptive immune systems' contributions to inflammation. Studies of the innate immune system have shown that inhibitors of GSK3 profoundly alter the repertoire of cytokines that are produced both by peripheral and central cells, reducing pro-inflammatory cytokines, and increasing anti-inflammatory cytokines. Furthermore, inhibitors of GSK3 promote tolerance to inflammatory stimuli, reducing inflammatory cytokine production upon repeated exposure. Studies of the adaptive immune system have shown that GSK3 regulates the production of cytokines by $T$ cells and the differentiation of T cells to subtypes, particularly Th17 cells. Regulation of transcription factors by GSK3 appears to play a prominent role in its regulation of immune responses, including of NF- $\mathrm{KB}$, cyclic AMP response element binding protein, and signal transducer and activator of transcription-3. In vivo studies have shown that GSK3 inhibitors ameliorate clinical symptoms of both peripheral and central inflammatory diseases, particularly experimental autoimmune encephalomyelitis, the animal model of MS. Therefore, the development and application of GSK3 inhibitors may provide a new therapeutic strategy to reduce neuroinflammation associated with many central nervous system diseases.

Keywords: glycogen synthase kinase-3, GSK3, inflammation, cytokines, EAE, multiple sclerosis, mood disorders, neurodegenerative diseases

\section{INTRODUCTION}

The immune system responds to infection or damage to attempt to restore homeostasis. Immune system responses are classified as adaptive or innate based on the activation timing and antigen presentation. Innate immune cells provide the first line of defense against pathogens, acting as sentinels to detect signs of distress. Upon the first signs of distress, activated sentinel cells of the innate immune system release soluble mediators of inflammation, such as cytokines and chemokines, to clear the pathogen. On the other hand, adaptive immunity is a slower response dependent on $\mathrm{T}$ cells and $\mathrm{B}$ cells reacting with antigen-presenting cells. Together, the innate and adaptive immune systems contribute to the process of inflammation, and dysregulation of either system can contribute to a variety of pathological conditions. Importantly, immune cell activation is usually rapidly reversed by anti-inflammatory and immunosuppressive functions in order to avoid damaging the host. Although the immune responses are mainly thought to be triggered in the periphery, there are also organ specialized immune cells, which exhibit unique immune function.

There is growing recognition that inflammatory signaling molecules have profound influences on many functions of the central nervous system (CNS). These effects include actions of both the innate and adaptive immune systems, as well as glia within the CNS (Raison et al., 2006; Dantzer et al., 2008; Miller et al., 2009; Miller, 2010). While it is important to remember that many of these neuroimmune actions are beneficial, as well as necessary, for a healthy CNS, research has been particularly focused on detrimental effects of neuroinflammation in association with psychiatric and neurodegenerative diseases. This has raised awareness that much remains to be learned about signaling mechanisms that regulate neuroinflammation, and that targeting regulators of neuroinflammation may prove to be a useful therapeutic strategy capable of affecting a diverse array of CNS disorders. Recent evidence is reviewed here demonstrating that glycogen synthase kinase-3 (GSK3) is an important regulator of both innate and adaptive immune system mediators that can profoundly affect the CNS.

\section{NEUROINFLAMMATION}

In contrast to other organs, the brain does not display a classical immune response but is capable of mounting its own inflammatory responses. The blood brain barrier serves to separate the brain's local inflammatory responses from systemic inflammation by limiting, but not entirely preventing, the penetration of 
peripheral inflammatory mediators and immune cells (Lampson, 1987; Fuchs and Bullard, 1988). This unique protection from systemic inflammation likely developed to protect neurons, since they are long-lived cells with limited capacity to recover from noxious insults. However, although for many years the immune privileged status of the CNS was misinterpreted to mean exclusion of immune cells, it is now evident that "immunosurveillance is an integral part of the functioning brain" (Schwartz and Shechter, 2010). In the CNS, microglia are the sentinel cells that constantly survey the environment and become activated to produce an inflammatory response to infection or damage (Kim and De Vellis, 2005). In conjunction with microglia responses, astrocytes are also well-established to contribute to neuroinflammatory responses (Lieberman et al., 1989; Hamby and Sofroniew, 2010). Acutely or chronically, these glial responses could be beneficial or detrimental because they allow microglia to migrate to afflicted sites where they produce cytokines and growth factors that can contribute to the recovery, or be deleterious, for affected neurons, and may contribute to many diseases of the nervous system (Matyszak, 1998; Correale and Villa, 2004; Campbell, 2005; Cartier et al., 2005; Hauwel et al., 2005; Kim and De Vellis, 2005; Imitola et al., 2006; Kielian, 2006; Schwartz et al., 2006). Thus, it is crucial to identify mechanisms that induce and regulate neuroinflammation. The prevalence of markers of inflammation associated with psychiatric and neurodegenerative diseases suggest there is prolonged activation and impaired down-regulation of neuroinflammation in these conditions, including influences by the peripheral immune system. Thus, it remains difficult to dissociate distinct contributions of the peripheral and CNS inflammatory systems, making it challenging to identify therapeutic targets to control neuroinflammation.

\section{GSK3 PROMOTES NEUROINFLAMMATION}

Inflammatory responses were first found to be promoted by GSK3 following stimulation of several types of toll-like receptors (TLR) in monocytes and peripheral blood mononuclear cells (Martin et al., 2005). This demonstrated that GSK3 is necessary for full stimulation of the production of several pro-inflammatory cytokines, such as interleukin-6 (IL-6), IL-1 $\beta$, and tumor necrosis factor- $\alpha(\mathrm{TNF} \alpha)$, and inhibitors of GSK3 greatly reduced the production of pro-inflammatory cytokines. Remarkably, in vivo administration of GSK3 inhibitors provided protection from endotoxin shock sufficiently enough to allow the survival of most mice from an otherwise lethal $\left(\mathrm{LD}_{100}\right)$ dose of lipopolysaccharide (LPS; Martin et al., 2005). This study showed for the first time the powerful ability of GSK3 inhibitors to shift the balance of the inflammatory response from pro-inflammatory to antiinflammatory, and revealed the therapeutic potential for these drugs in inflammatory conditions (Martin et al., 2005). These findings raised the novel possibility that inhibitors of GSK3 may prove to be beneficial in conditions involving inflammation (Jope et al., 2007).

The pro-inflammatory action of GSK3 and anti-inflammatory actions of its inhibitors have been demonstrated with a variety of inflammatory molecules and extended to several cell types (Gao et al., 2008; Wang et al., 2009a,b, 2011a; Gurrieri et al., 2010; Kao et al., 2010; Klamer et al., 2010; Baarsma et al., 2011; for review Beurel et al., 2010), including cells in the CNS that contribute to neuroinflammation. In LPS-stimulated microglia, GSK3 promotes the production of cytokines and other inflammatory molecules, such as IL-1 $\beta$, TNF $\alpha$, IL-6, IL-8, RANTES, CXCL-10, and nitric oxide (NO; Luna-Medina et al., 2005; Hashioka et al., 2007; Beurel and Jope, 2009b; Cheng et al., 2009; Huang et al., 2009; Yuskaitis and Jope, 2009). As in the periphery, NF-кB is thought to be a critical transcription factor targeted by GSK3 for promoting neuroinflammation (Yuskaitis and Jope, 2009; Wang et al., 2010), as discussed below. In addition to microglia, GSK3 also promotes cytokine production by astrocytes (Park et al., 2006; Beurel and Jope, 2010), in particular IL-6, and promotes the IL-6/signal transducer and activator of transcription-3 (STAT3)-dependent activation of glial fibrillary acidic protein (GFAP), which is a critical marker of astrogliosis (Beurel and Jope, 2008, 2009b). Tolerance is a mechanism whereby cells dampen their response to two consecutive identical stimuli, and the promotion of IL- 6 production by GSK3 was shown to also involve GSK3 counteracting LPSinduced tolerance for IL-6 production in astrocytes (Beurel and Jope, 2010).

Besides regulating cytokine production in glia, GSK3 also promotes migration and activation of glial cells (Beurel and Jope, 2008; Yuskaitis and Jope, 2009). Inhibition of GSK3 promotes microglial survival during oxygen-glucose deprivation (Chong et al., 2007) and treatment with erythropoietin both inhibited GSK3 and supported microglia survival (Li et al., 2006), actions that may contribute to minimizing permanent CNS damage.

Recently, inhibition of GSK3 was suggested to promote stabilization of the brain blood barrier (Ramirez et al., 2010). This was based on findings in cultured brain microvascular endothelial cells that GSK3 inhibition reduced the production of several inflammatory molecules and monocyte adhesion to and migration across cytokine-stimulated cells. Furthermore, in vivo inhibition of GSK3 reduced leukocyte adhesion to brain endothelium under inflammatory conditions.

\section{PRO-INFLAMMATORY MECHANISMS OF GSK3 GSK3 CAN PROMOTE PRO-INFLAMMATORY CYTOKINE PRODUCTION THROUGH NF-KB ACTIVATION}

Regulation of the inflammatory transcription factor NF- $\kappa$ B was found to be key for the pro-inflammatory actions of GSK3 (Martin et al., 2005; Gong et al., 2008a,b; Yuskaitis and Jope, 2009; Wang et al., 2010). Inhibitors of GSK3 reduced TLR-induced production of inflammatory cytokines by inhibiting the transcriptional activation of NF- $\mathrm{B}$ (Martin et al., 2005). This supported previous reports that GSK3 is necessary for the full transcriptional activity of NF- $\kappa$ B (Hoeflich et al., 2000), and that GSK3 supported NF- $\kappa \mathrm{B}$ transcriptional activity in a promoter-specific manner (Steinbrecher et al., 2005). This selective action of GSK3 $\beta$ on NF-кB-induced inflammatory gene expression may facilitate the therapeutic anti-inflammatory uses of GSK3 inhibitors since it indicates that inhibition of GSK3 will not interfere with all the actions of NF- $\kappa$ B. The role of GSK3 in the regulation of NF- $\kappa$ B in inflammation was further expanded by the demonstration of a role for GSK3 in the desensitization of LPS-induced inflammatory signaling by TNF $\alpha$ (Park et al., 2011). 


\section{GSK3 BLOCKS ANTI-INFLAMMATORY CYTOKINES}

Conversely to inflammatory signaling, GSK3 reduces the production of the anti-inflammatory cytokine IL-10, and inhibitors of GSK3 increased anti-inflammatory cytokine production (Martin et al., 2005; Hu et al., 2006; Antoniv and Ivashkiv, 2011; Ren et al., 2011). Inhibition of IL-10 production by GSK3 was reported to involve a competition for limiting amounts of $\mathrm{CBP} / \mathrm{p} 300$, with GSK3-promoted activation of NF- $\kappa$ B depleting the amount of $\mathrm{CBP} / \mathrm{p} 300$ available for cyclic AMP response element binding protein (CREB)-induced IL-10 production (Martin et al., 2005; Hu et al., 2006; Hofmann et al., 2010). It was also proposed that the down-regulation of IL-10 production by GSK3 contributes to the synergistic inflammatory signaling induced by co-treatment with interferons and TLR ligands ( $\mathrm{Hu}$ et al., 2006; Lin et al., 2008). Furthermore, the production of IL-10 by IFN $\beta$, thought to be important for the anti-inflammatory therapeutic properties of IFN $\beta$ in multiple sclerosis (MS) patients, was shown to be dependent on inhibition of GSK3 (Wang et al., 2011a).

TGF $\beta 1$ also has anti-inflammatory properties. Although the mechanism whereby TGF $\beta 1$ suppresses inflammation remains unclear, it has been proposed that TGF $\beta 1$ can antagonize the production of certain pro-inflammatory cytokines in response to inflammatory stimuli by inhibition of GSK3 to promote $\beta$-catenin signaling (Dai et al., 2011). Additionally, it is also thought that because TGF $\beta$ is required for the induction of regulatory $\mathrm{T}$ cells (Tregs), which produce IL-10, the anti-inflammatory action of TGF $\beta$ is mediated through its induction of Tregs in vivo where Tregs counteract the action of the pro-inflammatory effector $\mathrm{CD}^{+} \mathrm{T}$ cells and of the pro-inflammatory cytokines (Campbell and Koch, 2011). Recently, it was shown that inhibition of GSK3 increases the anti-inflammatory properties of Tregs by increasing $\beta$-catenin levels in response to TGF $\beta$ (Graham et al., 2010). GSK3 was also shown to regulate activation of Smad transcription factors (Fuentealba et al., 2007; Sapkota et al., 2007; Guo et al., 2008; Liang et al., 2008; Heldin et al., 2009), indicating a direct effect of GSK3 on the TGF $\beta$-induced signaling pathway.

Therefore, it appears that NF- $\mathrm{B}$ activation is a key proinflammatory pathway promoted by GSK3, whereas CREB and $\beta$-catenin are inhibited by GSK3 to maintain low levels of anti-inflammatory molecules.

\section{COOPERATION OF GSK3 WITH MTOR TO REGULATE CYTOKINE PRODUCTION}

A number of inflammatory signaling pathways converge on GSK3 to regulate cytokine production, reinforcing the concept that GSK3 has a central role in the regulation of cytokine production and other inflammatory outcomes. GSK3 promotes the activation of myeloid dendritic cells (DC) and their secretion of cytokines (Ono et al., 2007; Rodionova et al., 2007; Hoarau et al., 2008; Larabee et al., 2011; Liu et al., 2011; Wang et al., 2011b). During DC generation, inhibition of the mammalian target of rapamycin (mTOR) confers resistance to maturation, whereas inhibition of mTOR prior to TLR activation enhanced pro-inflammatory cytokine production. GSK3 activity was shown to be inhibited by the mTOR pathway and modulated the capacity of DCs to produce proinflammatory cytokines (Turnquist et al., 2010; Brown et al., 2011; Wang et al., 2011b). The production of cytokines by DCs also influences the differentiation of T helper (Th) cells (Ono et al., 2007) that are highly dependent on cytokines to differentiate toward different lineages (O'Shea and Paul, 2010).

\section{GSK3 INFLUENCES IMMUNE CELL FATE}

Glycogen synthase kinase-3 also regulates other transcription factors involved in inflammation besides NF- $\kappa \mathrm{B}$ and CREB, particularly STATs. This allows GSK3 to control the amplitude and the duration of inflammatory responses. Thus, it was shown that GSK3 participates in the synergistic action of IFN $\gamma$ on LPSinduced signaling in part by modulating the downstream signaling induced by IFN $\gamma$, the JAK/STAT pathway. Although GSK3 was not involved in the short term activation of IFN $\gamma$-induced STAT1 (Beurel and Jope, 2008), inhibitors of GSK3 blocked IFN $\gamma$-induced STAT1 activation at longer times in macrophages through SHP2 derepression (Tsai et al., 2009). Furthermore, a differential role of GSK3 in regulating the activation of different STAT subtypes was uncovered, as GSK3 was found to promote STAT3 and STAT5 activation, while GSK3 did not affect STAT6 activation (Beurel and Jope, 2008). This regulation of STAT3 activation by GSK3 may be particularly relevant for the signaling induced by IL-6, as well as for the production of IL- 6 in response to both LPS and the combination LPS and IFN $\gamma$ (Beurel and Jope, 2009a,b).

Although GSK3 has been mainly thought of as a regulator of cytokine production, an unexpected role of GSK3 was found to be in the regulation of the differentiation of Th subsets. Cytokines are key determinants for Th differentiation toward a particular lineage and STAT3 is a crucial instigator of the differentiation toward Th17 cells (O'Shea and Paul, 2010). Thus, it was found that GSK3 is required for Th17 cell production, perhaps due to both promoting IL-6 production and STAT3 activation (Harrington et al., 2005), although other processes likely also contribute to this action of GSK3 on Th17 cells (Beurel et al., 2011). This recent discovery that GSK3 promotes Th17 cell differentiation provides a new step in the understanding of the GSK3-dependent regulatory mechanisms of the immune system. Th17 cells are critical for the pathogenicity of many autoimmune diseases (Langrish et al., 2005; Ivanov et al., 2006; Komiyama et al., 2006), so the finding that inhibition of GSK3 blocked Th17 cell differentiation provides a new avenue of therapeutic intervention that may contribute to controlling Th17-driven diseases.

\section{SURVIVAL ADVANTAGES OF BLOCKING GSK3 ACTIVITY}

Glycogen synthase kinase-3 has long been known to promote cell death mediated by the intrinsic apoptotic pathway, whereas it protects from extrinsic apoptosis (Beurel and Jope, 2006; Sun et al., 2008). Several apoptosis-regulating properties of GSK3 have been identified in the immune system. Thus, for example, during the clonal expansion of activated T cells, there is induction of the activated T cell death (ACTD; Kondrack et al., 2003), which is thought to be due to a loss of access to survival signals. ACTD is thought to be critical to prevent autoimmune responses, but need to be tightly regulated because complete elimination of responding $\mathrm{T}$ cells would confer increased susceptibility to infections. GSK3 was shown to be required for ACTD and inhibition of GSK3 promotes survival of T cells (Sengupta et al., 2007). GSK3 was also found to be critical to induce apoptosis of DC (Hoarau et al., 2008). 
Altogether, GSK3 promotes pro-inflammatory cytokine production by regulating a network of transcription factors. GSK3 also receives signals in order to finely tune this cytokine production. But GSK3 also, intrinsically to immune cells, affects their maturation, differentiation, and survival rendering GSK3 an attractive target for therapeutic interventions.

\section{INFLAMMATION IN PSYCHIATRIC DISEASES}

The mood disorders depression and bipolar disorder are prevalent diseases with a high lifetime incidence of $\sim 20 \%$ in the US (Greden, 2001; Belmaker and Agam, 2008), but current treatments are often inadequate, as many patients do not respond or prematurely terminate treatment (Krishnan and Nestler, 2008). Much evidence has shown that mood disorders are associated with alterations of the immune system, especially increased markers of inflammation. For example, extensive evidence has demonstrated that inflammation promotes susceptibility to depression and impairs responses to antidepressants. Elevated serum levels of inflammatory cytokines, such as the cytokines IL- 6 and TNF $\alpha$, have been reported in patients with major depression or bipolar disorder (Anisman and Merali, 2003; O'Brien et al., 2004a, 2006, 2007; Schiepers et al., 2005; Raison et al., 2006; Dantzer et al., 2008; Miller et al., 2009; Miller, 2010). A significant portion of people develop depression following the therapeutic bolstering of immunity by interferon- $\alpha$ administration (Reichenberg et al., 2001; Wright et al., 2005; Prather et al., 2009). Depressive symptoms thought to be due to cytokines also occur after a mild activation of the innate immune system (Raison et al., 2006; Dantzer et al., 2008; Miller et al., 2009). Antidepressants are less effective in patients with activated inflammation, and antidepressant responses are improved in some patients by co-treatment with anti-inflammatory drugs (O'Brien et al., 2007; Roumestan et al., 2007; Dantzer et al., 2008; Miller et al., 2009; Rivest, 2009). Administration of drugs that inhibit the actions of cytokines or their signaling pathways, such as cyclooxygenase inhibitors and etanercept, improve mood in patients with inflammatory diseases (Mendlewicz et al., 2006; Muller et al., 2006; Tyring et al., 2006). These links demonstrating inflammation increases susceptibility to mood disorders have been recapitulated in rodents. For example, administration of individual inflammatory cytokines, or of LPS to induce inflammation, causes depression-like behaviors in rodents that are reversed by antidepressant administration (Dantzer and Kelley, 2007). Increased cytokine levels or administration of cytokines in rodents or humans have been reported to induce behavioral changes with characteristics similar to mood disorders (Licinio and Wong, 1999; Hayley et al., 2005; Simen et al., 2006). Importantly, psychological stress in both humans and rodents is sufficient to activate the production of inflammatory cytokines and to induce depressive symptoms (Anisman and Merali, 2003; O'Brien et al., 2006; Gabbay et al., 2009). Thus, there is much evidence that inflammation can precipitate depression and impair therapeutic responses. While it remains to be determined if inflammatory cytokines contribute to the onset or represent an outcome of mood disorders, it has been suggested that reducing inflammation may contribute to therapeutic interventions based on the depressive effects that cytokines can produce and on evidence that classical antidepressants are anti-inflammatory (Reynolds et al., 2005; Schiepers et al., 2005).
While many investigators have focused on actions of the innate immune system in depression, the impact of the adaptive immune system, especially $\mathrm{T}$ cells, remains poorly understood even though the innate and adaptive immune systems are highly integrated. Examinations of the effects of stress and depression on $\mathrm{T}$ cell responses demonstrated altered proliferation of peripheral blood mononuclear cells in response to stimulation with $\mathrm{T}$ cell mitogens in samples from patients with depression (Bartrop et al., 1977; Kronfol et al., 1983; Schleifer et al., 1983, 1984; Stein et al., 1991). T cell alterations also were indicated by in vivo measurements of $\mathrm{T}$ cell-mediated immune function in depressed patients (Hickie et al., 1993; Sephton et al., 2009). Studies of mechanisms implicated increased Fas-mediated $\mathrm{T}$ cell apoptosis (Eilat et al., 1999; Ivanova et al., 2007; Szuster-Ciesielska et al., 2008), reduced $\mathrm{T}$ cell responses to glucocorticoids that are elevated in major depression (Pariante and Miller, 2001), or increased cytokine levels that modulate $\mathrm{T}$ cell subtype production and responses (Cope et al., 1994, 1997; Lee et al., 2008). These and additional reports (Miller, 2010) of altered T cells in depression led to demonstrations that $\mathrm{T}$ cells mediate the negative impact of depression on health outcomes in depressed patients with infectious diseases or cancer.

Substantial evidence indicates that dysregulated GSK3 contributes to mood disorders (Li and Jope, 2010): brain GSK3 is abnormally active in postmortem human prefrontal cortex from depressed subjects (Karege et al., 2007), GSK3 is activated in mouse brain in the learned helplessness model of depression (Polter et al., 2010), antidepressants inhibit GSK3 (Li et al., 2004), reducing GSK3 activity ameliorates depression-like behaviors in rodents (Gould et al., 2003; Kaidanovich-Beilin et al., 2004; O'Brien et al., 2004b; Beaulieu et al., 2008), and abnormally active GSK3 in GSK3 knockin mice increases susceptibility to depression-like behaviors (Polter et al., 2010). Since inflammation is a candidate cause of increased susceptibility to depression, it is notable that GSK3 strongly promotes inflammation in the periphery (Martin et al., 2005) and CNS (Beurel and Jope, 2009b, 2010; Yuskaitis and Jope, 2009), which is reduced by GSK3 inhibitors. GSK3 knockin mice showed also a mild exacerbation of their depressive-like behavior in response to LPS administration compared to wild-type mice (Polter et al., 2010). Therefore, part of the therapeutic effects of the mood stabilizer lithium, as well as of antidepressants that inhibit GSK3, may come from their anti-inflammatory effects following inhibition of GSK3. However, further investigations are needed to definitively test if promotion of inflammation by GSK3 contributes to mood disorders.

\section{INFLAMMATION IN NEURODEGENERATIVE DISEASES}

Inflammatory markers, particularly increased levels of inflammatory cytokines and activated microglia and astrocytes, have been reported in many neurodegenerative diseases, such as Alzheimer's disease (AD), Parkinson's disease (PD), and amyotrophic lateral sclerosis, as well as MS, which is generally considered an autoimmune disease (Amor et al., 2010; Glass et al., 2010; Philips and Robberecht, 2011). This may be due to impaired mechanisms of inflammation resolution or persistent stimulation of inflammatory responses, such as may be caused by the generation of "danger" signals from degenerating neurons that activate damage-associated molecular patterns (DAMPs). Activation of the 
inflammatory system has beneficial effects, such as phagocytosis of dead cells and production of factors bolstering neuronal function and neurogenesis. However, it is generally thought that long-term inflammation associated with neurodegenerative diseases exacerbates the diseases by releasing signaling molecules that impair neuronal function and survival, increasing the impairments associated with the primary disease lesion.

\section{ALZHEIMER'S DISEASE}

Alzheimer's disease is a severe, progressive neurodegenerative disease with a growing prevalence and only modestly effective therapies are available. There are two classical neuropathological features of $\mathrm{AD}$ : intraneuronal filamentous aggregates of hyperphosphorylated tau and other proteins called neurofibrillary tangles, and extracellular deposits of aggregated amyloid- $\beta$ (A $\beta$ ) peptides called amyloid plaques. The levels of many cytokines, such as IL-1 $\beta$, IL-6, and TNF $\alpha$, and chemokines are upregulated in $\mathrm{AD}$, as previously reviewed (Akiyama et al., 2000; Block and Hong, 2005; Sastre et al., 2006). This inflammation and increased cytokine production is also exhibited by transgenic mouse models of AD (Benzing et al., 1999; Matsuoka et al., 2001). Activation of astrocytes and microglia and the ensuing production of inflammatory molecules has been reported to be stimulated by degenerating neurons, neurofibrillary tangles, and $\mathrm{A} \beta$ and other cleavage products of amyloid precursor protein, and activated astrocytes and microglia are found surrounding amyloid plaques in $\mathrm{AD}$ brain (Bach et al., 2001; Combs et al., 2001; Ho et al., 2005). Inflammation may contribute to the increased risk for $\mathrm{AD}$ following traumatic brain injury or diabetes, both of which can cause increased inflammation, as well as to the prevalent co-morbidity of depression with $\mathrm{AD}$, since much evidence links inflammation with depression as discussed above. Many investigations have reported evidence that hyperactive GSK3 in AD contributes to both of its neuropathological hallmarks by phosphorylating tau and promoting $\mathrm{A} \beta$ production (Jope and Johnson, 2004; Lesort and Jope, 2010) and to neuronal death (Beurel and Jope, 2006; Mines et al., 2011). These many links between AD and GSK3 have led to a substantial effort to develop GSK3 inhibitors for treating AD (Hooper et al., 2008; Martinez and Perez, 2008; Muyllaert et al., 2008; Hernandez et al., 2010). GSK3 inhibitors reduce inflammatory mediators implicated in $\mathrm{AD}$, such as $\mathrm{NO}$ (Yuskaitis and Jope, 2009) and inflammatory cytokines (Beurel et al., 2010). Considering the evidence for inflammation contributing to AD pathology and that GSK3 promotes inflammation, interventions with GSK3 inhibitors may also be beneficial by reducing the inflammation that is thought to exacerbate neurodegenerative processes in $\mathrm{AD}$.

\section{PARKINSON'S DISEASE}

Like many other neurodegenerative diseases, substantial evidence indicates that neuroinflammation contributes to PD, and its models in rodents. For example, activated inflammatory processes in the substantia nigra have been implicated in the loss of dopaminergic neurons in PD patients and in animal models of PD (Esposito et al., 2007; Hald et al., 2007; Mcgeer and Mcgeer, 2008; Barnum and Tansey, 2010), and some (Gagne and Power, 2010), but not all (Wahner et al., 2007; Driver et al., 2011), studies have indicated that non-steroidal anti-inflammatory drug use reduces the risk of PD. However, the innate immune system may not be acting alone in promoting PD. Evidence has been reported of activated $\mathrm{T}$ cells in the substantia nigra in rodent PD models (Kurkowska-Jastrzebska et al., 1999) and postmortem PD brains (Brochard et al., 2009), and elimination of $\mathrm{T}$ cells attenuated dopaminergic neuron loss in rodent PD models (Brochard et al., 2009). As in AD, there is evidence both that GSK3 contributes to neuronal degenerative processes in PD (King et al., 2001; Chen et al., 2004) and that neurotoxic mechanisms, such as $\alpha$-synuclein in PD, activate GSK3 (Duka et al., 2009; Yuan et al., 2010). Thus, inhibition of GSK3 may protect susceptible neurons from degeneration and reduce the inflammation that appears to promote neurodegenerative processes in PD.

\section{MULTIPLE SCLEROSIS}

Multiple sclerosis appears to result from aberrant innate and adaptive immune system actions in the CNS, likely initiated by an autoimmune response that causes inflammation, demyelination, and neuronal degeneration (Weiner, 2008). Thus, in contrast to the other neurodegenerative diseases that appear to initiate with neuronal insults, MS is initiated by aberrant actions of the adaptive immune system. Studies of MS patients and of the animal model of MS (experimental autoimmune encephalomyelitis, EAE) have implicated the Th17 and Th1 subsets of Th cells as key mediators of the disease (Langrish et al., 2005; Ivanov et al., 2006; Tzartos et al., 2008). This first wave of adaptive immune system activity and inflammation seems to be followed by a second wave of neuroinflammation, and both are thought to contribute to the death of oligodendrocytes. Thus, inflammation with activation of microglia and astrocytes are well-established components of MS and targeting the response of these cells has been explored (Kang et al., 2010).

The crucial inflammatory component of MS suggests that inhibitors of GSK3 may provide some amelioration of the disease. Indeed, in EAE, administration of lithium to inhibit GSK3 effectively prevents the disease and almost completely terminates ongoing disease (De Sarno et al., 2008; Beurel et al., 2011). Notably, inhibitors of GSK3 also prevent production of Th17 cells that are critical for the disease (Beurel et al., 2011), suggesting that GSK3 inhibitors provide at least two actions that may contribute to alleviation of MS.

\section{CONCLUSION}

Glycogen synthase kinase-3 is now well-established to contribute to inflammatory processes in the periphery, and growing evidence indicates that GSK3 also promotes neuroinflammation. This action appears to be largely the result of GSK3 promoting the activities of transcription factors that mediate inflammatory responses, particularly NF- $\kappa$ B and STAT3. Furthermore, although both paralogs of GSK3, GSK $3 \alpha$ and GSK3 $\beta$, share many common actions, there is increasing evidence that they can also have non-redundant functions (Hoeflich et al., 2000; Liang and Chuang, 2006; Force and Woodgett, 2009). Most of the studies on inflammation focused on GSK3 $\beta$, mainly because more tools have been developed for studying GSK3 $\beta$. However, there is a differential role of GSK3 $\alpha$ and GSK $3 \beta$ in the regulation of IL- 6 production (Beurel and 
Jope, 2008). Therefore, identifying differential role for GSK3 $\alpha$ and GSK $3 \beta$ may be a promising avenue for future studies. Importantly, GSK3 has been implicated in pathological processes of psychiatric and neurodegenerative diseases that also exhibit increased inflammatory activation, such as mood disorders, AD, PD, and MS. Thus, GSK3 may provide a feasible therapeutic target to

\section{REFERENCES}

Akiyama, H., Barger, S., Barnum, S., Bradt, B., Bauer, J., Cole, G. M., Cooper, N. R., Eikelenboom, P., Emmerling, M., Fiebich, B. L., Finch, C. E., Frautschy, S., Griffin, W. S., Hampel, H., Hull, M., Landreth, G., Lue, L., Mrak, R., Mackenzie, I. R., Mcgeer, P. L., O’Banion, M. K., Pachter, J., Pasinetti, G., Plata-Salaman, C., Rogers, J., Rydel, R., Shen, Y., Streit, W., Strohmeyer, R., Tooyoma, I., Van Muiswinkel, F. L., Veerhuis, R., Walker, D., Webster, S., Wegrzyniak, B., Wenk, G., and Wyss-Coray, T. (2000). Inflammation and Alzheimer's disease. Neurobiol. Aging 21, 383-421.

Amor, S., Puentes, F., Baker, D., and Van Der Valk, P. (2010). Inflammation in neurodegenerative diseases. Immunology 129, 154-169.

Anisman, H., and Merali, Z. (2003). Cytokines, stress and depressive illness: brain-immune interactions. Ann. Med. 35, 2-11.

Antoniv, T. T., and Ivashkiv, L. B. (2011). Interleukin-10-induced gene expression and suppressive function are selectively modulated by the PI3K-Akt-GSK3 pathway. Immunology 132, 567-577.

Baarsma, H. A., Meurs, H., Halayko, A. J., Menzen, M. H., Schmidt, M., Kerstjens, H. A., and Gosens, R. (2011). Glycogen synthase kinase-3 regulates cigarette smoke extract- and IL-1\{beta\}-induced cytokine secretion by airway smooth muscle. Am. J. Physiol. Lung Cell. Mol. Physiol. 300, L910-L919.

Bach, J. H., Chae, H. S., Rah, J. C., Lee, M. W., Park, C. H., Choi, S. H., Choi, J. K., Lee, S. H., Kim, Y. S., Kim, K. Y., Lee, W. B., Suh, Y. H., and Kim, S. S. (2001). C-terminal fragment of amyloid precursor protein induces astrocytosis. J. Neurochem. 78, 109-120.

Barnum, C. J., and Tansey, M. G. (2010). Modeling neuroinflammatory pathogenesis of Parkinson's disease. Prog. Brain Res. 184, 113-132.

Bartrop, R. W., Luckhurst, E., Lazarus, L., Kiloh, L. G., and Penny, R. (1977). Depressed lymphocyte function after bereavement. Lancet 1, 834-836.
Beaulieu, J. M., Zhang, X., Rodriguiz, R. M., Sotnikova, T. D., Cools, M. J., Wetsel, W. C., Gainetdinov, R. R., and Caron, M. G. (2008). Role of GSK3 beta in behavioral abnormalities induced by serotonin deficiency. Proc. Natl. Acad. Sci. U.S.A. 105, 1333-1338.

Belmaker, R. H., and Agam, G. (2008). Major depressive disorder. N. Engl. J. Med. 358, 55-68.

Benzing, W. C., Wujek, J. R., Ward, E. K., Shaffer, D., Ashe, K. H., Younkin, S. G., and Brunden, K. R. (1999). Evidence for glial-mediated inflammation in aged $\operatorname{APP}(\mathrm{SW})$ transgenic mice. Neurobiol. Aging 20, 581-589.

Beurel, E., and Jope, R. S. (2006). The paradoxical pro- and anti-apoptotic actions of GSK3 in the intrinsic and extrinsic apoptosis signaling pathways. Prog. Neurobiol. 79, 173-189.

Beurel, E., and Jope, R. S. (2008). Differential regulation of STAT family members by glycogen synthase kinase-3. J. Biol. Chem. 283, 21934-21944.

Beurel, E., and Jope, R. S. (2009a). Glycogen synthase kinase3 promotes the synergistic action of interferon-gamma on lipopolysaccharideinduced IL-6 production in RAW264.7 cells. Cell Signal. 21, 978-985.

Beurel, E., and Jope, R. S. (2009b). Lipopolysaccharide-induced interleukin-6 production is controlled by glycogen synthase kinase- 3 and STAT3 in the brain. $J$. Neuroinflammation 6, 9.

Beurel, E., and Jope, R. S. (2010). Glycogen synthase kinase- 3 regulates inflammatory tolerance in astrocytes. Neuroscience 169, 1063-1070.

Beurel, E., Michalek, S. M., and Jope, R. S. (2010). Innate and adaptive immune responses regulated by glycogen synthase kinase3 (GSK3). Trends Immunol. 31, 24-31.

Beurel, E., Yeh, W. I., Michalek, S. M., Harrington, L. E., and Jope, R. S. (2011). Glycogen synthase kinase- 3 is an early determinant in the differentiation of pathogenic Th17 cells. J. Immunol. 186, 1391-1398.

control inflammation along with ameliorating other pathological processes in several diseases of the CNS.

\section{ACKNOWLEDGMENTS}

Research in the author's laboratory was funded by the NIMH (MH090236, MH038752, MH095380).

Block, M. L., and Hong, J. S. (2005). Microglia and inflammationmediated neurodegeneration: multiple triggers with a common mechanism. Prog. Neurobiol. 76, 77-98.

Brochard, V., Combadiere, B., Prigent, A., Laouar, Y., Perrin, A., BerayBerthat, V., Bonduelle, O., AlvarezFischer, D., Callebert, J., Launay, J. M., Duyckaerts, C., Flavell, R. A., Hirsch, E. C., and Hunot, S. (2009). Infiltration of CD4+ lymphocytes into the brain contributes to neurodegeneration in a mouse model of Parkinson disease. J. Clin. Invest. 119, 182-192.

Brown, J., Wang, H., Hajishengallis, G. N., and Martin, M. (2011). TLR-signaling networks: an integration of adaptor molecules, kinases, and cross-talk. J. Dent. Res. 90, 417-427.

Campbell, D. J., and Koch, M. A. (2011). Phenotypical and functional specialization of FOXP3+ regulatory T cells. Nat. Rev. Immunol. 11, 119-130.

Campbell, I. L. (2005). Cytokinemediated inflammation, tumorigenesis, and disease-associated JAK/STAT/SOCS signaling circuits in the CNS. Brain Res. Brain Res. Rev. 48, 166-177.

Cartier, L., Hartley, O., DuboisDauphin, M., and Krause, K. H. (2005). Chemokine receptors in the central nervous system: role in brain inflammation and neurodegenerative diseases. Brain Res. Brain Res. Rev. 48, 16-42.

Chen, G., Bower, K. A., Ma, C., Fang, S., Thiele, C. J., and Luo, J. (2004). Glycogen synthase kinase 3beta (GSK3beta) mediates 6-hydroxydopamine-induced neuronal death. FASEB J. 18, 1162-1164.

Cheng, Y. L., Wang, C. Y., Huang, W. C., Tsai, C. C., Chen, C. L., Shen, C. F., Chi, C. Y., and Lin, C. F. (2009). Staphylococcus aureus induces microglial inflammation via a glycogen synthase kinase 3betaregulated pathway. Infect. Immun. 77, 4002-4008.

Chong, Z. Z., Li, F., and Maiese, K. (2007). The pro-survival pathways of $\mathrm{mTOR}$ and protein kinase B target glycogen synthase kinase- $3 \beta$ and nuclear factor- $\kappa \mathrm{B}$ to foster endogenous microglial cell protection. Int. J. Mol. Med. 19, 263-272.

Combs, C. K., Karlo, J. C., Kao, S. C., and Landreth, G. E. (2001). Beta-Amyloid stimulation of microglia and monocytes results in TNFalpha-dependent expression of inducible nitric oxide synthase and neuronal apoptosis. J. Neurosci. 21, 1179-1188.

Cope, A. P., Liblau, R. S., Yang, X. D., Congia, M., Laudanna, C., Schreiber, R. D., Probert, L., Kollias, G., and Mcdevitt, H. O. (1997). Chronic tumor necrosis factor alters $\mathrm{T}$ cell responses by attenuating $\mathrm{T}$ cell receptor signaling. J. Exp. Med. 185, 1573-1584.

Cope, A. P., Londei, M., Chu, N. R., Cohen, S. B., Elliott, M. J., Brennan, F. M., Maini, R. N., and Feldmann, M. (1994). Chronic exposure to tumor necrosis factor (TNF) in vitro impairs the activation of $\mathrm{T}$ cells through the $\mathrm{T}$ cell receptor/CD3 complex; reversal in vivo by anti-TNF antibodies in patients with rheumatoid arthritis. J. Clin. Invest. 94, 749-760.

Correale, J., and Villa, A. (2004). The neuroprotective role of inflammation in nervous system injuries. $J$. Neurol. 251, 1304-1316.

Dai, C., Wen, X., He, W., and Liu, Y. (2011). Inhibition of proinflammatory RANTES expression by TGFbetal is mediated by glycogen synthase kinase-3beta-dependent betacatenin signaling. J. Biol. Chem. 286, 7052-7059.

Dantzer, R., and Kelley, K. W. (2007). Twenty years of research on cytokine-induced sickness behavior. Brain Behav. Immun. 21, 153-160.

Dantzer, R., O'Connor, J. C., Freund, G. G., Johnson, R. W., and Kelley, K. W. (2008). From inflammation to sickness and depression: when the immune system subjugates the brain. Nat. Rev. Neurosci. 9 , 46-56.

De Sarno, P., Axtell, R. C., Raman, C., Roth, K. A., Alessi, D. R., and Jope, R. S. (2008). Lithium prevents and ameliorates experimental autoimmune encephalomyelitis. J. Immunol. 181, 338-345. 
Driver, J. A., Logroscino, G., Lu, L., Gaziano, J. M., and Kurth, T. (2011). Use of non-steroidal anti-inflammatory drugs and risk of Parkinson' disease: nested casecontrol study. BMJ 342, d198.

Duka, T., Duka, V., Joyce, J. N., and Sidhu, A. (2009). Alpha-Synuclein contributes to GSK-3beta-catalyzed Tau phosphorylation in Parkinson's disease models. FASEB J. 23, 2820-2830.

Eilat, E., Mendlovic, S., Doron, A., Zakuth, V., and Spirer, Z. (1999). Increased apoptosis in patients with major depression: a preliminary study. J. Immunol. 163, 533-534.

Esposito, E., Di Matteo, V., Benigno, A., Pierucci, M., Crescimanno, G., and Di Giovanni, G. (2007). Nonsteroidal anti-inflammatory drugs in Parkinson's disease. Exp. Neurol. 205, 295-312.

Force, T., and Woodgett, J. R. (2009). Unique and overlapping functions of GSK-3 isoforms in cell differentiation and proliferation and cardiovascular development. J. Biol. Chem. 284, 9643-9647.

Fuchs, H. E., and Bullard, D. E. (1988). Immunology of transplantation in the central nervous system. Appl. Neurophysiol. 51, 278-296.

Fuentealba, L. C., Eivers, E., Ikeda, A., Hurtado, C., Kuroda, H., Pera, E. M., and De Robertis, E. M. (2007). Integrating patterning signals: Wnt/GSK3 regulates the duration of the BMP/Smad1 signal. Cell 131, 980-993.

Gabbay, V., Klein, R. G., Alonso, C. M., Babb, J. S., Nishawala, M., De Jesus, G., Hirsch, G. S., HottingerBlanc, P. M., and Gonzalez, C. J. (2009). Immune system dysregulation in adolescent major depressive disorder. J. Affect. Disord. 115, 177-182.

Gagne, J. J., and Power, M. C. (2010). Anti-inflammatory drugs and risk of Parkinson disease: a meta-analysis. Neurology 74, 995-1002.

Gao, H. K., Yin, Z., Zhou, N., Feng, X. Y., Gao, F., and Wang, H. C. (2008). Glycogen synthase kinase 3 inhibition protects the heart from acute ischemia-reperfusion injury via inhibition of inflammation and apoptosis. J. Cardiovasc. Pharmacol. 52, 286-292.

Glass, C. K., Saijo, K., Winner, B., Marchetto, M. C., and Gage, F. H. (2010). Mechanisms underlying inflammation in neurodegeneration. Cell 140, 918-934.

Gong, R., Ge, Y., Chen, S., Liang, E., Esparza, A., Sabo, E., Yango, A., Gohh, R., Rifai, A., and Dworkin,
L. D. (2008a). Glycogen synthase kinase 3beta: a novel marker and modulator of inflammatory injury in chronic renal allograft disease. Am. J. Transplant. 8, 1852-1863.

Gong, R., Rifai, A., Ge, Y., Chen, S., and Dworkin, L. D. (2008b). Hepatocyte growth factor suppresses proinflammatory NFkappaB activation through GSK3beta inactivation in renal tubular epithelial cells. J. Biol. Chem. 283, 7401-7410.

Gould, T. D., Gray, N. A., and Manji, H. K. (2003). Effects of a glycogen synthase kinase-3 inhibitor, lithium, in adenomatous polyposis coli mutant mice. Pharmacol. Res. 48, 49-53.

Graham, J. A., Fray, M., De Haseth, S., Lee, K. M., Lian, M. M., Chase, C. M. Madsen, J. C., Markmann, J., Benichou, G., Colvin, R. B., Cosimi, A. B., Deng, S., Kim, J., and Alessandrini, A. (2010). Suppressive regulatory T cell activity is potentiated by glycogen synthase kinase 3 \{beta\} inhibition. J. Biol. Chem. 285, 32852-32859.

Greden, J. F. (2001). The burden of recurrent depression: causes, consequences, and future prospects. $J$. Clin. Psychiatry 62(Suppl. 22), 5-9.

Guo, X., Ramirez, A., Waddell, D. S., Li, Z., Liu, X., and Wang, X. F. (2008). Axin and GSK3ß control Smad3 protein stability and modulate TGFß signaling. Genes Dev. 22, 106-120.

Gurrieri, C., Piazza, F., Gnoato, M., Montini, B., Biasutto, L., Gattazzo, C., Brunetta, E., Cabrelle, A., Cinetto, F., Niero, R., Facco, M., Garbisa, S., Calabrese, F., Semenzato, G., and Agostini, C. (2010). 3-(2,4dichlorophenyl)-4-(1-methyl-1Hindol-3-yl)-1H-pyrrole-2,5-dione (SB216763), a glycogen synthase kinase-3 inhibitor, displays therapeutic properties in a mouse model of pulmonary inflammation and fibrosis. J. Pharmacol. Exp. Ther. 332, 785-794.

Hald, A., Van Beek, J., and Lotharius, J. (2007). Inflammation in Parkinson's disease: causative or epiphenomenal? Subcell. Biochem. 42, 249-279.

Hamby, M. E., and Sofroniew, M. V. (2010). Reactive astrocytes as therapeutic targets for CNS disorders. Neurotherapeutics 7, 494-506.

Harrington, L. E., Hatton, R. D., Mangan, P. R., Turner, H., Murphy, T. L., Murphy, K. M., and Weaver, C. T. (2005). Interleukin 17-producing CD4+ effector T cells develop via a lineage distinct from the $\mathrm{T}$ helper type 1 and 2 lineages. Nat. Immunol. 6, 1123-1132.

Hashioka, S., Klegeris, A., Monji, A., Kato, T., Sawada, M., Mcgeer, P. L., and Kanba, S. (2007). Antidepressants inhibit interferon- $\gamma$-induced microglial production of IL- 6 and nitric oxide. Exp. Neurol. 206, 33-42.

Hauwel, M., Furon, E., Canova, C. Griffiths, M., Neal, J., and Gasque, P. (2005). Innate (inherent) control of brain infection, brain inflammation and brain repair: the role of microglia, astrocytes, "protective" glial stem cells and stromal ependymal cells. Brain Res. Brain Res. Rev. 48, 220-233.

Hayley, S., Poulter, M. O., Merali, Z., and Anisman, H. (2005). The pathogenesis of clinical depression: stressorand cytokine-induced alterations of neuroplasticity. Neuroscience 135 659-678.

Heldin, C. H., Landstrom, M., and Moustakas, A. (2009). Mechanism of TGF-beta signaling to growth arrest, apoptosis, and epithelialmesenchymal transition. Curr. Opin. Cell Biol. 21, 166-176.

Hernandez, F., Gomez De Barreda, E. Fuster-Matanzo, A., Lucas, J. J., and Avila, J. (2010). GSK3: a possible link between beta amyloid peptide and tau protein. Exp. Neurol. 223 322-325.

Hickie, I., Hickie, C., Lloyd, A., Silove, D., and Wakefield, D. (1993). Impaired in vivo immune responses in patients with melancholia. Br. J. Psychiatry 162 651-657.

Ho, G. J., Drego, R., Hakimian, E. and Masliah, E. (2005). Mechanisms of cell signaling and inflammation in Alzheimer's disease. Curr. Drug Targets Inflamm. Allergy 4 247-256.

Hoarau, C., Martin, L., Faugaret, D., Baron, C., Dauba, A., AubertJacquin, C., Velge-Roussel, F., and Lebranchu, Y. (2008). Supernatant from bifidobacterium differentially modulates transduction signaling pathways for biological functions of human dendritic cells. PLoS ONE 3, e2753. doi: 10.1371/journal.pone. 0002753

Hoeflich, K. P., Luo, J., Rubie, E. A., Tsao, M. S., Jin, O., and Woodgett, J. R. (2000). Requirement for glycogen synthase kinase-3beta in cell survival and NF-kappaB activation. Nature 406, 86-90.

Hofmann, C., Dunger, N., Scholmerich, J., Falk, W., and Obermeier, F. (2010). Glycogen synthase kinase 3beta: a master regulator of toll-like receptor-mediated chronic intestinal inflammation. Inflamm. Bowel Dis. 16, 1850-1858.

Hooper, C., Killick, R., and Lovestone, S. (2008). The GSK3 hypothesis of
Alzheimer's disease. J. Neurochem 104, 1433-1439.

Hu, X., Paik, P. K., Chen, J., Yarilina, A., Kockeritz, L., Lu, T. T., Woodgett, J. R., and Ivashkiv, L. B. (2006) IFN- $\gamma$ suppresses IL-10 production and synergizes with TLR2 by regulating GSK3 and CREB/AP-1 proteins. Immunity 24, 563-574.

Huang, W. C., Lin, Y. S., Wang, C. Y., Tsai, C. C., Tseng, H. C., Chen, C. L., Lu, P. J., Chen, P. S., Qian, L., Hong, J. S., and Lin, C. F. (2009). Glycogen synthase kinase- 3 negatively regulates anti-inflammatory interleukin-10 for lipopolysaccharide-induced iNOS/NO biosynthesis and RANTES production in microglial cells. Immunology 128 , e275-e286.

Imitola, J., Chitnis, T., and Khoury, S. J. (2006). Insights into the molecular pathogenesis of progression in multiple sclerosis: potential implications for future therapies. Arch. Neurol. 63 , 25-33.

Ivanov, I. I., Mckenzie, B. S., Zhou, L., Tadokoro, C. E., Lepelley, A., Lafaille, J. J., Cua, D. J., and Littman, D. R. (2006). The orphan nuclear receptor RORgammat directs the differentiation program of proinflammatory IL-17+ T helper cells. Cell 126, 1121-1133.

Ivanova, S. A., Semke, V. Y., Vetlugina, T. P., Rakitina, N. M., Kudyakova, T. A., and Simutkin, G. G. (2007). Signs of apoptosis of immunocompetent cells in patients with depression. Neurosci. Behav. Physiol. 37, 527-530.

Jope, R. S., and Johnson, G. V. (2004). The glamour and gloom of glycogen synthase kinase-3. Trends Biochem. Sci. 29, 95-102.

Jope, R. S., Yuskaitis, C. J., and Beurel, E. (2007). Glycogen synthase kinase3 (GSK3): inflammation, diseases, and therapeutics. Neurochem. Res. 32, 577-595.

Kaidanovich-Beilin, O., Milman, A., Weizman, A., Pick, C. G. and Eldar-Finkelman, H. (2004). Rapid antidepressive-like activity of specific glycogen synthase kinase-3 inhibitor and its effect on beta-catenin in mouse hippocampus. Biol. Psychiatry 55, 781-784.

Kang, Z., Altuntas, C. Z., Gulen, M. F., Liu, C., Giltiay, N., Qin, H., Liu, L., Qian, W., Ransohoff, R. M., Bergmann, C., Stohlman, S., Tuohy, V. K., and Li, X. (2010). Astrocyte-restricted ablation of interleukin-17-induced Act1mediated signaling ameliorates autoimmune encephalomyelitis. Immunity 32, 414-425. 
Kao, T. C., Shyu, M. H., and Yen, G. C. (2010). Glycyrrhizic acid and 18beta-glycyrrhetinic acid inhibit inflammation via PI3K/Akt/GSK3beta signaling and glucocorticoid receptor activation. J. Agric. Food Chem. 58, 8623-8629.

Karege, F., Perroud, N., Burkhardt, S., Schwald, M., Ballmann, E., La Harpe, R., and Malafosse, A. (2007). Alteration in kinase activity but not in protein levels of protein kinase $B$ and glycogen synthase kinase-3beta in ventral prefrontal cortex of depressed suicide victims. Biol. Psychiatry 61, 240-245.

Kielian, T. (2006). Toll-like receptors in central nervous system glial inflammation and homeostasis. J. Neurosci. Res. 83, 711-730.

Kim, S. U., and De Vellis, J. (2005). Microglia in health and disease. $J$. Neurosci. Res. 81, 302-313.

King, T. D., Bijur, G. N., and Jope, R. S. (2001). Caspase-3 activation induced by inhibition of mitochondrial complex I is facilitated by glycogen synthase kinase-3beta and attenuated by lithium. Brain Res. 919, 106-114.

Klamer, G., Song, E., Ko, K. H., O’Brien, T. A., and Dolnikov, A. (2010). Using small molecule GSK3beta inhibitors to treat inflammation. Curr. Med. Chem. 17, 2873-2881.

Komiyama, Y., Nakae, S., Matsuki, T., Nambu, A., Ishigame, $\mathrm{H}$., Kakuta, S., Sudo, K., and Iwakura, Y. (2006). IL-17 plays an important role in the development of experimental autoimmune encephalomyelitis. J. Immunol. 177, 566-573.

Kondrack, R. M., Harbertson, J., Tan, J. T., Mcbreen, M. E., Surh, C. D., and Bradley, L. M. (2003). Interleukin 7 regulates the survival and generation of memory CD4 cells. J. Exp. Med. 198, 1797-1806.

Krishnan, V., and Nestler, E. J. (2008). The molecular neurobiology of depression. Nature 455, 894-902.

Kronfol, Z., Silva, J. Jr., Greden, J., Dembinski, S., Gardner, R., and Carroll, B. (1983). Impaired lymphocyte function in depressive illness. Life Sci. 33, 241-247.

Kurkowska-Jastrzebska, I., Wronska, A., Kohutnicka, M., Czlonkowski, A., and Czlonkowska, A. (1999). The inflammatory reaction following 1-methyl-4-phenyl-1,2,3, 6-tetrahydropyridine intoxication in mouse. Exp. Neurol. 156, 50-61.

Lampson, L. (1987). Molecular bases of the immune response to neural antigens. Trends Neurosci. 10, 211-216.

Langrish, C. L., Chen, Y., Blumenschein, W. M., Mattson, J., Basham, B., Sedgwick, J. D., Mcclanahan, T., Kastelein, R. A., and Cua, D. J. (2005). IL23 drives a pathogenic $\mathrm{T}$ cell population that induces autoimmune inflammation. J. Exp. Med. 201, 233-240.

Larabee, J. L., Maldonado-Arocho, F. J., Pacheco, S., France, B., Degiusti, K., Shakir, S. M., Bradley, K. A., and Ballard, J. D. (2011). Gsk-3 activation is important for anthrax edema toxin induced dendritic cell maturation and antxr2 expression in macrophages. Infect. Immun. 79, 3302-3309.

Lee, L. F., Lih, C. J., Huang, C. J., Cao, T., Cohen, S. N., and Mcdevitt, H. O. (2008). Genomic expression profiling of TNF-alpha-treated BDC2.5 diabetogenic CD4+ T cells. Proc. Natl. Acad. Sci. U.S.A. 105, 10107-10112.

Lesort, M., and Jope, R.S. (2010). "Multiple roles of glycogen synthase kinase-3 in Alzheimer's disease," in Emerging Drugs and Tarets for Alzheimer's Disease, ed. A. Martinez (Cambridge: Royal Society of Chemistry), 153-172.

Li, F., Chong, Z. Z., and Maiese, K. (2006). Microglial integrity is maintained by erythropoietin through integration of Akt and its substrates of glycogen synthase kinase- $3 \beta, \beta$-catenin, and nuclear factor-кB. Curr. Neurovasc. Res. 3, 187-201.

Li, X., and Jope, R. S. (2010). Is glycogen synthase kinase- 3 a central modulator in mood regulation? Neuropsychopharmacology 35, 2143-2154.

Li, X., Zhu, W., Roh, M. S., Friedman, A. B., Rosborough, K., and Jope, R. S. (2004). In vivo regulation of glycogen synthase kinase-3beta (GSK3beta) by serotonergic activity in mouse brain. Neuropsychopharmacology 29, 1426-1431.

Liang, M. H., and Chuang, D. M. (2006). Differential roles of glycogen synthase kinase-3 isoforms in the regulation of transcriptional activation. J. Biol. Chem. 281, 30479-30484.

Liang, M. H., Wendland, J. R., and Chuang, D. M. (2008). Lithium inhibits Smad3/4 transactivation via increased CREB activity induced by enhanced PKA and AKT signaling. Mol. Cell. Neurosci. 37, 440-453.

Licinio, J., and Wong, M. L. (1999). The role of inflammatory mediators in the biology of major depression: central nervous system cytokines modulate the biological substrate of depressive symptoms, regulate stress-responsive systems, and contribute to neurotoxicity and neuroprotection. Mol. Psychiatry 4 , 317-327.

Lieberman, A. P., Pitha, P. M., Shin, H. S., and Shin, M. L. (1989). Production of tumor necrosis factor and other cytokines by astrocytes stimulated with lipopolysaccharide or a neurotropic virus. Proc. Natl. Acad. Sci. U.S.A. 86, 6348-6352.

Lin, C. F., Tsai, C. C., Huang, W. C., Wang, C. Y., Tseng, H. C., Wang, Y., Kai, J. I., Wang, S. W. and Cheng, Y. L. (2008). IFNgamma synergizes with LPS to induce nitric oxide biosynthesis through glycogen synthase kinase-3inhibited IL-10. J. Cell. Biochem. 105 , 746-755.

Liu, K. J., Lee, Y. L., Yang, Y. Y., Shih, N. Y., Ho, C. C., Wu, Y. C., Huang, T. S., Huang, M. C., Liu, H. C., Shen, W. W., and Leu, S. J. (2011). Modulation of the development of human monocyte-derived dendritic cells by lithium chloride. J. Cell. Physiol. 226, 424-433.

Luna-Medina, R., Cortes-Canteli, M., Alonso, M., Santos, A., Martinez, A. and Perez-Castillo, A. (2005). Regulation of inflammatory response in neural cells in vitro by thiadiazolidinones derivatives through peroxisome proliferator-activated receptor gamma activation. J. Biol. Chem. 280, 21453-21462.

Martin, M., Rehani, K., Jope, R. S. and Michalek, S. M. (2005). Tolllike receptor-mediated cytokine production is differentially regulated by glycogen synthase kinase 3 . Nat. Immunol. 6, 777-784.

Martinez, A., and Perez, D. I. (2008) GSK-3 inhibitors: a ray of hope for the treatment of Alzheimer's disease? J. Alzheimers Dis. 15, 181-191.

Matsuoka, Y., Picciano, M., Malester, B. Lafrancois, J., Zehr, C., Daeschner, J. M., Olschowka, J. A., Fonseca, M. I., O'Banion, M. K., Tenner, A. J. Lemere, C. A., and Duff, K. (2001). Inflammatory responses to amyloidosis in a transgenic mouse model of Alzheimer's disease. Am. J. Pathol. 158, 1345-1354.

Matyszak, M. K. (1998). Inflammation in the CNS: balance between immunological privilege and immune responses. Prog. Neurobiol. 56, 19-35.

Mcgeer, P. L., and Mcgeer, E. G. (2008). Glial reactions in Parkinson's disease. Mov. Disord. 23, 474-483.

Mendlewicz, J., Kriwin, P., Oswald, P., Souery, D., Alboni, S., and Brunello, N. (2006). Shortened onset of action of antidepressants in major depression using acetylsalicylic acid augmentation: a pilot open-label study. Int. Clin. Psychopharmacol. 21, 227-231.

Miller, A. H. (2010). Depression and immunity: a role for T cells? Brain Behav. Immun. 24, 1-8.

Miller, A. H., Maletic, V., and Raison, C. L. (2009). Inflammation and its discontents: the role of cytokines in the pathophysiology of major depression. Biol. Psychiatry 65, 732-741.

Mines, M. A., Beurel, E., and Jope, R. S. (2011). Regulation of survival mechanisms in ALzheimer's disease by glycogen synthase kinase-3 (GSK3). Int. J. Alzhimers Dis. 2011, 1-12.

Muller, N., Schwarz, M. J., Dehning, S., Douhe, A., Cerovecki, A., Goldstein-Muller, B., Spellmann, I. Hetzel, G., Maino, K., Kleindienst, N., Moller, H. J., Arolt, V., and Riedel, M. (2006). The cyclooxygenase-2 inhibitor celecoxib has therapeutic effects in major depression: results of a double-blind, randomized, placebo controlled, add-on pilot study to reboxetine. Mol. Psychiatry $11,680-684$.

Muyllaert, D., Kremer, A., Jaworski, T., Borghgraef, P., Devijver, H., Croes, S., Dewachter, I., and Van Leuven, F. (2008). Glycogen synthase kinase3beta, or a link between amyloid and tau pathology? Genes Brain Behav. 7(Suppl. 1), 57-66.

O'Brien, S. M., Scott, L. V., and Dinan, T. G. (2004a). Cytokines: abnormalities in major depression and implications for pharmacological treatment. Hum. Psychopharmacol. 19, 397-403.

O’Brien, W. T., Harper, A. D., Jove, F., Woodgett, J. R., Maretto, S., Piccolo, S., and Klein, P. S. (2004b). Glycogen synthase kinase-3beta haploinsufficiency mimics the behavioral and molecular effects of lithium. $J$. Neurosci. 24, 6791-6798.

O'Brien, S. M., Scully, P., Fitzgerald, P., Scott, L. V., and Dinan, T. G. (2007). Plasma cytokine profiles in depressed patients who fail to respond to selective serotonin reuptake inhibitor therapy. J. Psychiatr. Res. 41, 326-331.

O’Brien, S. M., Scully, P., Scott, L. V., and Dinan, T. G. (2006). Cytokine profiles in bipolar affective disorder focus on acutely ill patients. J. Affect. Disord. 90, 263-267.

Ono, T., Yanagawa, Y., Iwabuchi, K., Nonomura, K., and Onoe, K. (2007). Glycogen synthase kinase 3 activity during development of bone marrow-derived dendritic cells (DCs) essential for the DC function to induce $\mathrm{T}$ helper 2 polarization. Immunology 122, 189-198. 
O'Shea, J. J., and Paul, W. E. (2010). Mechanisms underlying lineage commitment and plasticity of helper CD4+ T cells. Science 327, 1098-1102.

Pariante, C. M., and Miller, A. H. (2001). Glucocorticoid receptors in major depression: relevance to pathophysiology and treatment. Biol. Psychiatry 49, 391-404.

Park, C., Lee, S., Cho, I. H., Lee, H. K., Kim, D., Choi, S. Y., Oh, S. B., Park, K., Kim, J. S., and Lee, S. J. (2006). TLR3-mediated signal induces proinflammatory cytokine and chemokine gene expression in astrocytes: differential signaling mechanisms of TLR3-induced IP-10 and IL-8 gene expression. Glia 53, 248-256.

Park, S. H., Park-Min, K. H., Chen, J., $\mathrm{Hu}, \mathrm{X}$, and Ivashkiv, L. B. (2011). Tumor necrosis factor induces GSK3 kinase-mediated cross-tolerance to endotoxin in macrophages. Nat. Immunol. 12, 607-615.

Philips, T., and Robberecht, W. (2011). Neuroinflammation in amyotrophic lateral sclerosis: role of glial activation in motor neuron disease. Lancet Neurol. 10, 253-263.

Polter, A., Beurel, E., Yang, S., Garner, R., Song, L., Miller, C. A., Sweatt, J. D., Mcmahon, L., Bartolucci, A. A., Li, X., and Jope, R. S. (2010). Deficiency in the inhibitory serinephosphorylation of glycogen synthase kinase- 3 increases sensitivity to mood disturbances. Neuropsychopharmacology 35, 1761-1774.

Prather, A. A., Rabinovitz, M., Pollock, B. G., and Lotrich, F. E. (2009). Cytokine-induced depression during IFN-alpha treatment: the role of IL-6 and sleep quality. Brain Behav. Immun. 23, 1109-1116.

Raison, C. L., Capuron, L., and Miller, A. H. (2006). Cytokines sing the blues: inflammation and the pathogenesis of depression. Trends Immunol. 27, 24-31.

Ramirez, S. H., Fan, S., Zhang, M., Papugani, A., Reichenbach, N., Dykstra, H., Mercer, A. J., Tuma, R. F., and Persidsky, Y. (2010). Inhibition of glycogen synthase kinase 3beta (GSK3beta) decreases inflammatory responses in brain endothelial cells. Am. J. Pathol. 176, 881-892.

Reichenberg, A., Yirmiya, R., Schuld, A., Kraus, T., Haack, M., Morag, A., and Pollmacher, T. (2001). Cytokineassociated emotional and cognitive disturbances in humans. Arch. Gen. Psychiatry 58, 445-452.

Ren, F., Duan, Z., Cheng, Q., Shen, X., Gao, F., Bai, L., Liu, J., Busuttil, R. W.,
Kupiec-Weglinski, J. W., and Zhai, Y. (2011). The inhibition of glycogen synthase kinase 3 beta ameliorates liver ischemia reperfusion injury via an IL-10-mediated immune regulatory mechanism. Hepatology 54, 687-696.

Reynolds, J. L., Ignatowski, T. A., Sud, R., and Spengler, R. N. (2005). An antidepressant mechanism of desipramine is to decrease tumor necrosis factor-alpha production culminating in increases in noradrenergic neurotransmission. Neuroscience 133, 519-531.

Rivest, S. (2009). Regulation of innate immune responses in the brain. Nat. Rev. Immunol. 9, 429-439.

Rodionova, E., Conzelmann, M., Maraskovsky, E., Hess, M., Kirsch, M., Giese, T., Ho, A. D., Zoller, M., Dreger, P., and Luft, T. (2007). GSK-3 mediates differentiation and activation of proinflammatory dendritic cells. Blood 109, 1584-1592.

Roumestan, C., Michel, A., Bichon, F., Portet, K., Detoc, M., Henriquet, C., Jaffuel, D., and Mathieu, M. (2007). Anti-inflammatory properties of desipramine and fluoxetine. Respir. Res. 3, 8-35.

Sapkota, G., Alarcon, C., Spagnoli, F. M., Brivanlou, A. H., and Massague, J. (2007). Balancing BMP signaling through integrated inputs into the Smad1 linker. Mol. Cell 25, 441-454.

Sastre, M., Klockgether, T., and Heneka, M. T. (2006). Contribution of inflammatory processes to Alzheimer's disease: molecular mechanisms. Int. J. Dev. Neurosci. $24,167-176$.

Schiepers, O. J., Wichers, M. C., and Maes, M. (2005). Cytokines and major depression. Prog. Neuropsychopharmacol. Biol. Psychiatry 29, 201-217.

Schleifer, S. J., Keller, S. E., Camerino, M., Thornton, J. C., and Stein, M. (1983). Suppression of lymphocyte stimulation following bereavement. JAMA 250, 374-377.

Schleifer, S. J., Keller, S. E., Meyerson, A. T., Raskin, M. J., Davis, K. L., and Stein, M. (1984). Lymphocyte function in major depressive disorder. Arch. Gen. Psychiatry 41, 484-486.

Schwartz, M., Butovsky, O., Bruck, W., and Hanisch, U. K. (2006). Microglial phenotype: is the commitment reversible? Trends Neurosci. $29,68-74$.

Schwartz, M., and Shechter, R. (2010). Systemic inflammatory cells fight off neurodegenerative disease. Nat. Rev. Neurol. 6, 405-410.

Sengupta, S., Jayaraman, P., Chilton, P. M., Casella, C. R., and Mitchell, T. C. (2007). Unrestrained glycogen synthase kinase- 3 beta activity leads to activated $\mathrm{T}$ cell death and can be inhibited by natural adjuvant. $J$. Immunol. 178, 6083-6091.

Sephton, S. E., Dhabhar, F. S., Keuroghlian, A. S., Giese-Davis, J. Mcewen, B. S., Ionan, A. C., and Spiegel, D. (2009). Depression, cortisol, and suppressed cell-mediated immunity in metastatic breast cancer. Brain Behav. Immun. 23 1148-1155.

Simen, B. B., Duman, C. H., Simen, A. A., and Duman, R. S. (2006). TNFalpha signaling in depression and anxiety: behavioral consequences of individual receptor targeting. Biol. Psychiatry 59, 775-785.

Stein, M., Miller, A. H., and Trestman, R. L. (1991). Depression, the immune system, and health and illness. Findings in search of meaning. Arch. Gen. Psychiatry 48, 171-177.

Steinbrecher, K. A., Wilson, W., 3rd, Cogswell, P. C., and Baldwin, A. S. (2005). Glycogen synthase kinase $3 B$ functions to specify gene-specific, NF- $\kappa B-d e p e n d e n t$ transcription. Mol. Cell. Biol. 25, 8444-8455.

Sun, M., Song, L., Li, Y., Zhou, T., and Jope, R. S. (2008). Identification of an antiapoptotic protein complex at death receptors. Cell Death Differ. 15 , 1887-1900.

Szuster-Ciesielska, A., Slotwinska, M., Stachura, A., MarmurowskaMichalowska, H., Dubas-Slemp, H., Bojarska-Junak, A., and KandeferSzerszen, M. (2008). Accelerated apoptosis of blood leukocytes and oxidative stress in blood of patients with major depression. Prog. Neuropsychopharmacol. Biol. Psychiatry 32, 686-694.

Tsai, C. C., Kai, J. I., Huang, W. C. Wang, C. Y., Wang, Y., Chen, C. L., Fang, Y. T., Lin, Y. S., Anderson, R., Chen, S. H., Tsao, C. W., and Lin, C. F. (2009). Glycogen synthase kinase-3beta facilitates IFN-gamma-induced STAT1 activation by regulating Src homology-2 domain-containing phosphatase 2 . J. Immunol. 183, 856-864.

Turnquist, H. R., Cardinal, J., Macedo, C., Rosborough, B. R., Sumpter, T. L., Geller, D. A., Metes, D., and Thomson, A. W. (2010). mTOR and GSK3 shape the CD4+ T-cell stimulatory and differentiation capacity of myeloid DCs after exposure to LPS. Blood 115, 4758-4769.
Tyring, S., Gottlieb, A., Papp, K., Gordon, K., Leonardi, C., Wang, A., Lalla, D., Woolley, M., Jahreis, A., Zitnik, R., Cella, D., and Krishnan, R. (2006). Etanercept and clinical outcomes, fatigue, and depression in psoriasis: double-blind placebocontrolled randomised phase III trial. Lancet 367, 29-35.

Tzartos, J. S., Friese, M. A., Craner, M. J., Palace, J., Newcombe, J., Esiri, M. M. and Fugger, L. (2008). Interleukin17 production in central nervous system-infiltrating $\mathrm{T}$ cells and glial cells is associated with active disease in multiple sclerosis. Am. J. Pathol. 172, 146-155.

Wahner, A. D., Bronstein, J. M., Bordelon, Y. M., and Ritz, B. (2007). Nonsteroidal anti-inflammatory drugs may protect against Parkinson disease. Neurology 69, 1836-1842.

Wang, H., Brown, J., Garcia, C. A., Tang, Y., Benakanakere, M. R., Greenway, T., Alard, P., Kinane, D. F., and Martin, M. (2011a). The role of glycogen synthase kinase 3 in regulating IFNbeta-mediated IL-10 production. $J$. Immunol. 186, 675-684.

Wang, H., Brown, J., Gu, Z., Garcia, C. A., Liang, R., Alard, P., Beurel, E., Jope, R. S., Greenway, T., and Martin, M. (2011b). Convergence of the mammalian target of rapamycin complex 1- and glycogen synthase kinase 3-beta-signaling pathways regulates the innate inflammatory response. J. Immunol. 186, 5217-5226.

Wang, M. J., Huang, H. Y., Chen, W. F., Chang, H. F., and Kuo, J. S (2010). Glycogen synthase kinase3beta inactivation inhibits tumor necrosis factor-alpha production in microglia by modulating nuclear factor kappaB and MLK3/JNK signaling cascades. J. Neuroinflammation 7, 99.

Wang, Y., Feng, W., Xue, W., Tan, Y., Hein, D. W., Li, X. K., and Cai, L. (2009a). Inactivation of GSK3beta by metallothionein prevents diabetes-related changes in cardiac energy metabolism, inflammation, nitrosative damage, and remodeling. Diabetes 58, 1391-1402.

Wang, Y., Huang, W. C., Wang, C. Y., Tsai, C. C., Chen, C. L., Chang, Y. T., Kai, J. I., and Lin, C. F. (2009b). Inhibiting glycogen synthase kinase- 3 reduces endotoxaemic acute renal failure by down-regulating inflammation and renal cell apoptosis. Br. J. Pharmacol. 157, 1004-1013.

Weiner, H. L. (2008). A shift from adaptive to innate immunity: a potential mechanism of disease progression 
in multiple sclerosis. J. Neurol. 255(Suppl. 1), 3-11.

Wright, C. E., Strike, P. C., Brydon, L., and Steptoe, A. (2005). Acute inflammation and negative mood: mediation by cytokine activation. Brain Behav. Immun. 19, 345-350.

Yuan, Y., Sun, J., Zhao, M., Hu, J., Wang, X., Du, G., and Chen, N. H. (2010). Overexpression of alphasynuclein down-regulates BDNF expression. Cell. Mol. Neurobiol. 30, 939-946.

Yuskaitis, C. J., and Jope, R. S. (2009). Glycogen synthase kinase3 regulates microglial migration, inflammation, and inflammationinduced neurotoxicity. Cell. Signal. 21, 264-273.

Conflict of Interest Statement: The author declares that the research was conducted in the absence of any commercial or financial relationships that could be construed as a potential conflict of interest.

Received: 19 June 2011; paper pending published: 20 July 2011; accepted: 09 August 2011; published online: 31 August 2011.

Citation: Beurel E (2011) Regulation by glycogen synthase kinase-3 of inflammation and $T$ cells in CNS diseases. Front. Mol. Neurosci. 4:18. doi 10.3389/fnmol.2011.00018

Copyright (c) 2011 Beurel. This is an open-access article subject to a nonexclusive license between the authors and Frontiers Media SA, which permits use, distribution and reproduction in other forums, provided the original authors and source are credited and other Frontiers conditions are complied with. 